\title{
Do Parenting Style and Adolescents' Self-esteem Contribute to Mental Health Problems among Young Adolescents in Malaysia? An Adolescents' Perspective
}

\author{
I.D. Noordin ${ }^{a}$, I.B.Idris ${ }^{a}$, R. Hod ${ }^{b}$, N.A. Muhammad ${ }^{a}$, H. Mohd Yusoff ${ }^{a}$, N.A.Anuar ${ }^{a}$, Q. Mohd Ghazali \\ aDepartment of Community Health, UKM Medical Centre, Jalan Yaacob Latif, Bandar Tun Razak, 56000, \\ Wilayah Persekutuan, Kuala Lumpur. \\ bDepartment of Family Medicine, UKM Medical Centre, Jalan Yaakob Latif, Bandar Tun Razak, 56000, Wilayah \\ Persekutuan, Kuala Lumpur.
}

\section{ABSTRACT}

Introduction: Adolescence is a crucial phase in life, as this is the time when they are developing their identity, while at the same time forming relationships with others, including their family members. This study investigated adolescents' mental health status in Malaysia and its associated factors including self -esteem and parenting style that are experienced by them. Materials and Methods: A cross-sectional study was conducted among 248 school-going adolescents aged 13 and 14 years in Selangor, Malaysia. The validated Malay version of the Strengths and Difficulties Questionnaire (SDQ) was utilized to assess adolescents' mental health status. In addition, the adolescents' self-esteem was also assessed using the Rosenberg Self-Esteem Scale Questionnaire while the Parental Bonding Instrument was used to assess their parent's parenting style. Results: Almost $20 \%$ of the adolescents were found to have mental health problems such as emotional and conduct problems, hyperactivity disorder and peer problems. Using multivariate analysis, factors that were associated with mental health problems were family income ( $A O R=2.788,95 \% \mathrm{Cl}=1.397,5.563)$, adolescents' self-esteem (AOR $=0.799,95 \% \mathrm{Cl}=0.668,0.955)$ and their perception on parental control $(A O R=1.175,95 \% \mathrm{Cl}=1.020,1.353)$. Conclusion: This study shows that one fifth of these adolescents had mental health problems. Low socio-economic factors, over controlling parents and poor self-esteem were associated with these problems. In conclusion, it is important to educate parents on effective parenting style, as improper parenting may cause psychological distress among adolescents. Improving families' socioeconomic status and adolescents' self-esteem can also enhance their mental health and well-being.

KEYWORDS: Adolescent, Mental health problems, Parenting style, Self-esteem, Over-controlling

\section{INTRODUCTION}

Mental health problems have been one of the top contributors of disability-adjusted life years (DALYs) among adolescents. Globally, depression and intentional self-harm have been identified as among the top five causes of healthy live lost, disability or premature death among adolescents. ${ }^{1}$ The Malaysian National Health Morbidity Survey (NHMS) 2015, found that the overall prevalence of mental health problems among children aged 5 to 15 that include emotional, conduct, hyperactivity and peer

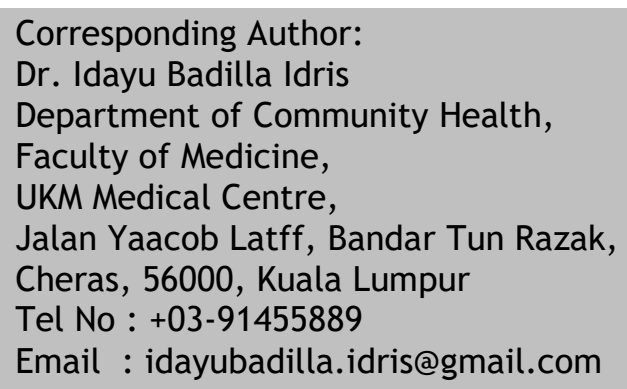

problems, was $12 \% .^{2}$ In comparison to a similar survey conducted in $2011^{3}$, the prevalence of mental health problems among children of similar age group was $20 \%$. During the earlier survey $^{3}$, mental health problems were defined using a bigger perspective, which include speech abnormality, sleep problems, history of epilepsy, as well as frequent somatic complaints such as headache, frequent running away from home, stealing things from home, unexplained anxiety, slow learner, poor social interaction and frequent incontinence. Studies have also shown that the prevalence was higher among males and those who were socio-economically disadvantaged. ${ }^{4}$ Although there was a variation in the definition of mental health problems between the Malaysian surveys conducted in 2011 and 2015, there is still a need to have an understanding on the factors that may increase the occurrence of mental health 
problems among Malaysian adolescents. The prevalence of depression tends to be higher in older aged children as opposed in younger children (24\% vs $10.5 \%$ ) as shown in a survey conducted among 307 adolescents aged between 11 to 16 in Kuala Lumpur. ${ }^{5}$ Another study involving 495 children conducted in Klang Valley, Malaysia, concluded that the prevalence of mental health problems were $8.5 \%$ when reported by parents using the Strength and Difficulties Questionnaire (SDQ). ${ }^{6}$

Parents are usually the closest persons in adolescents' life. The type of parenting styles experienced by the adolescent can be identified objectively by recalling their usual interactions with their parents such as by using the Parental Bonding Instrument. ${ }^{7,8}$ Types of parenting differ according to interplay of care, overprotection and autonomy factors. ' Parenting style may influence adolescents' personality and mental health status. This is shown by a study in Taiwan which was conducted among male adults, which found that previous parenting behaviours had an indirect effect towards adults' mental health status, such as adjustment disorder and hyperventilation syndrome through personality building. ${ }^{10}$ Parental bonding, such as lesser caring attitude and overprotectiveness were associated with increased risk of eating disturbances among students. ${ }^{11}$ Certain types of parenting can also be mediated by the student's lack of selfunderstanding, low self-esteem and external locus of control $^{12}$. Neglectful and abusive parenting were found to be associated with the development of mental health problems among adolescents, which may persist during their adulthood and even in later life. $^{13}$

On the other hand, the adolescent's self-esteem may significantly influence their mental wellbeing. Adolescent who have high self-esteem are expected to have better academic achievement, social life, coping skills and thus lesser mental health issues. A study in France had found that adolescents with mental illness such as depression, anxiety, eating disorder, personality disorder, or conduct disorder had significantly lower self-esteem compared to adolescents among normal population. ${ }^{14}$ Similar results was exhibited in some Asian countries that showed adolescents with poor family relationship, had lower self-esteem and were more likely to have depression ${ }^{15,16}$. This is verified through a survey which was conducted among secondary school students in Malaysia which has shown that feeling of isolation, social pressure and poor self-esteem are associated with mental depression. ${ }^{17}$

However, studies on parenting and adolescent health issues, particularly mental health problems are still limited in Malaysia. The aim of this paper was to measure the prevalence of mental health problems among adolescents aged 13 and 14 years in Selangor, Malaysia and to determine the association between their sociodemographic background, parenting behaviours and adolescent's self-esteem with their mental health problems.

\section{METHODOLOGY}

\section{Study design and selection of respondents}

This was a cross sectional study conducted in October 2015 among adolescents aged 13 and 14 years in Selangor, Malaysia. The study sample size was calculated using $a=0.05$ and $B=0.95$. We used the mental health prevalence of $12 \%^{2}$ found by NHMS among 148,139 Secondary 1 and Secondary 2 students in Selangor. Using this prevalence rate, the calculated sample size was found to be 350 . Taking into account $20 \%$ of dropout rate, 420 questionnaires were finally distributed.

By using multistage random sampling procedure, 10 secondary schools were selected from a list of 33 public secondary schools in Selangor, each school receiving 42 questionnaires. From the 10 schools, the counsellor of each school was contacted and invited to take part in this study. When a particular school agreed to participate, the respective classrooms were selected based on random sampling. The counsellors then approached the respective class teachers from the selected classes, and they were subsequently handed the information sheets, consent forms and a set of self-administered questionnaires to be given to parents via the students. Students who were randomly selected to be in this study were aged between 13 to 14 years, are well versed in the Malay language and received parental consent. Student who did not receive parental consent and were absent on the day of data collection were excluded from taking part in this study. These students were instructed to bring all the documents home. Parents who agreed their adolescents to participate, were requested to sign the parental consent forms and complete the socio-economic and 
demographic questionnaires.

\section{Study Instrument and variables}

This study was conducted using self-administered questionnaires which consisted of four parts. The first part which was answered by parents included socio-economic and demographic profiles including the family income, housing area, number of siblings, parent's marital status and past medical history. Parents completed the first part of the questionnaire at home after signing the consent form and the students would then return the questionnaires back to their school teachers. The second part of the questionnaire consisted the assessment of adolescent's mental health status, their self-esteem and perception of their parents' parenting behaviours. These questionnaires were answered by adolescents during allocated sessions in their classrooms.

The Strengths and Difficulties Questionnaires (SDQ) assessed the mental health status of the adolescents. The SDQ is available from http:// www.sdqinfo.org and this questionnaire can be downloaded freely ${ }^{18}$. This questionnaire has been translated into the Malay Language ${ }^{19}$ and it has been widely used in adolescent's mental health research as it is easy to complete and user friendly due to its positive attributes items. It also allows comparisons to be made between different categories of informants ${ }^{20,21}$. The SDQ comprises of 25 items that covered emotional, conduct, hyperactivity, peer problems and pro-social skills domains. The total difficulties scores are the summation scores of all domains except the social skills domain. The total difficulties scores ranged from 0 to 40, which measures emotional, conduct, hyperactivity and peer problems scores. The adolescents were categorized as having mental health problem if the total difficulties scores were between 20 and $40^{18}$. SDQ was also used in the recent Malaysian National Health Morbidity Survey $2015^{2}$. The parent-report questionnaire of the SDQ is reliable and has also been validated in the Malay Language. ${ }^{19}$

In terms of assessment of self-esteem, students were given the Rosenberg Self-Esteem questionnaire ${ }^{22}$, which has also been validated in the Malay Language ${ }^{23}$. It is a 10 -item questionnaire which measures self-worth by measuring the positive or negative feelings of the respondents. The total scores are derived by adding the rated scale for each item and this questionnaire have also been found to be reliable ${ }^{23}$. Higher scores correlates with higher self-esteem.

Adolescent's perception of their parent's parenting behaviours was assessed using the Parental Bonding Instrument $(\mathrm{PBI}) .^{7,8,24}$ This instrument has been widely used over the last decade. ${ }^{25}$ The PBI has been translated and validated in Malaysia and available in the Malay language (PBI-M). ${ }^{9}$ This study used the validated $\mathrm{PBI}-\mathrm{M}$ version that has 20 items in which 10 items were for parental care domain, 5 items were for parental control domain and 5 items were for parental autonomy domain. These variables were calculated based on Likert Scale answers. Higher scores in each domain indicated higher parental care, control and allowance of autonomy, respectively.

For ethnicity, respondents were categorised into Bumiputra that included Malays, Sabah and Sarawak indigenous people while Non-Bumiputra were respondents from Chinese, Indians and other ethnicities. The variable for family's income was also categorised based on the Household Income and Basic Amenities Survey Report by Department of Statistics Malaysia in $2016^{26}$ where families with average monthly income of RM3, 000 and above were considered as having medium to high income.

\section{ETHICAL ISSUES}

This research has obtained approval from the Ethics Committee UKM Medical Centre (GGPM-2014-063) and Ministry of Education Malaysia. All adolescents who took part in this study had been given permission to participate by their parents. During the administration of these questionnaires, the researcher was available to answer any query from respondents.

\section{STATISTICAL ANALYSIS}

Data was analysed using IBM Statistical Package Social Science version 22. Mean and standard deviation were used to describe continuous variable, and percentages and frequencies were used for categorical variables. Bivariate analyses of categorical variables were conducted using either the Chi-square or Fisher's Exact when more than 1 
cell have expected count of less than 5. The Independent Sample t-test was utilized to analyse continuous variables namely the self-esteem scores and parental bonding scores. Non-parametric MannWhitney $U$ test was used in non-normally distributed continuous data.

These analyses were applied to determine the associations of independent variables with mental health problems among adolescents. Subsequently, the independent variables that were found to be significant in bivariate analysis were analysed using multiple logistic regression in order to identify the adjusted odds ratio of the variables that increased the likelihood of mental health problems among these adolescents. The significant variables were analysed using backward stepwise likelihood ratio test, to finally develop the final model of factors associated with mental health. The statistically significance level was pre-set at $p$ value of less than 0.05 .

\section{RESULTS}

From a total of 420 questionnaires that were distributed to the adolescents, 360 parents consented and completed the questionnaire, giving a response rate of $86 \%$. However, only 248 questionnaires were returned with complete answers and thus included in the analyses.

Almost $65 \%$ of the questionnaire were answered by mothers while the rest were filled by fathers. There were almost equal proportions of Secondary 1 and Secondary 2 students aged 13 and 14 years, respectively. There were more female respondents than male with ratio of 3 to 1 . Majority $(77.4 \%)$ of the adolescents resided in urban housing area. More than half of the adolescents (58.9\%) were from families with middle to high socio-economic background and they were usually from a family of three or more children $\mathbf{( 7 5 . 8 \% )}$

Table I shows the frequencies of total difficulties scores and other domains in the Strength and Difficulty Questionnaires. There were 49 adolescents (19.8\%) who were found to have mental health problems. Most problems were from the domains of peer problems and prosocial behaviours where 1 in 4 adolescents had abnormal scores. The other affected domains were conduct problems $(21 \%)$, emotional problems (17.3\%) and hyperactivity problems (8.9\%).
Table I: Prevalence of mental health problems among school going adolescents, $\mathrm{N}=248$ Strengths and Difficulties Questionnaire (SDQ) Scoring as reported by the adolescents

\begin{tabular}{llcc}
\hline \multicolumn{1}{c}{ Domain } & \multicolumn{1}{c}{ Score } & $\mathrm{n}$ & $\%$ \\
\hline $\begin{array}{l}\text { Total Difficulties } \\
\text { Scores }\end{array}$ & Abnormal (20 to 40) & 49 & 19.8 \\
& Normal (0 to 14) & 199 & 80.2 \\
Emotional & Abnormal (7 to 10) & 43 & 17.3 \\
Symptoms Score & Normal (0 to 4) & 205 & 82.7 \\
Conduct & Abnormal (6 to 10) & 52 & 21.0 \\
Problems Score & Normal (0 to 3) & 196 & 79.0 \\
& Abnormal (8 to 10) & 22 & 8.9 \\
Hyperactivity & Normal (0 to 5) & 226 & 91.1 \\
Score & Abnormal (5 to 10) & 62 & 25.0 \\
Peer Problems & Normal (0 to 2) & 186 & 75.0 \\
Score & Abnormal (0 to 4) & 62 & 25.0 \\
& Normal (7 to 10) & 186 & 75.0 \\
\hline $\begin{array}{l}\text { Prosocial } \\
\text { Behaviour Score }\end{array}$ & &
\end{tabular}

Table II reveals that family income was significantly associated with mental health problems among the adolescents. Table III showed the result of independent sample t-test which found that selfesteem and parenting control showed significant association with mental health problems among the adolescents. Other socio-demographic profiles, i.e. parental allowance of autonomy and parental care were not found to be associated with mental health problems among adolescents.

Table IV shows that low family monthly income was the most important factor that was associated with adolescent's mental health problems, followed by perception of parental control and adolescent's selfesteem. Adolescents from low income family had two and a half time odds of having mental health problems. Those who perceived to have higher level of parental control have 1.21 times odds of having mental health problems. Finally, higher self-esteem was associated with lower odds of having mental health problems indicating that self-esteem had acted as a protective factor.

\section{DISCUSSION}

Prevalence of mental health problems among the adolescents in this study was $19.8 \%$. This prevalence is higher compared to the prevalence reported in the recent Malaysian National Health Morbidity Survey (NHMS) conducted in 2015 which was 12\%. This could 
Table II: Bivariate analysis of socio-demographic factors and mental health problems in adolescents, N=248

\begin{tabular}{|c|c|c|c|c|c|c|c|c|}
\hline \multicolumn{2}{|c|}{ Factors } & \multicolumn{2}{|c|}{$\begin{array}{l}\text { No mental } \\
\text { health } \\
\text { problems }\end{array}$} & \multicolumn{2}{|c|}{$\begin{array}{l}\text { Having mental } \\
\text { health } \\
\text { problems }\end{array}$} & \multirow[t]{2}{*}{ Total (\%) } & \multirow[t]{2}{*}{$x^{2}$ test } & \multirow[t]{2}{*}{$p$ value } \\
\hline & & $\mathrm{n}$ & $\%$ & $\mathrm{n}$ & $\%$ & & & \\
\hline \multirow[t]{2}{*}{ Gender } & Male & 55 & 87.3 & 8 & 12.7 & $63(25.4 \%)$ & 2.655 & 0.103 \\
\hline & Female & 144 & 77.8 & 41 & 22.2 & $\begin{array}{c}185 \\
(73.6 \%)\end{array}$ & & \\
\hline \multirow[t]{2}{*}{ Age } & Secondary 1 & 97 & 77.6 & 28 & 22.4 & $\begin{array}{c}125 \\
(50.5 \%)\end{array}$ & 1.11 & 0.292 \\
\hline & Secondary 2 & 102 & 82.9 & 21 & 17.1 & $\begin{array}{c}123 \\
(49.5 \%)\end{array}$ & & \\
\hline \multirow[t]{2}{*}{ Ethnicity } & Bumiputera & 159 & 78.3 & 44 & 21.7 & 203 (81.9\%) & 2.418 & 0.120 \\
\hline & Non-Bumiputra & 39 & 88.6 & 5 & 11.4 & $\begin{array}{c}45 \\
(18.1 \%)\end{array}$ & & \\
\hline \multirow{2}{*}{ Housing Area } & Urban & 154 & 80.2 & 38 & 19.8 & $192(77.4)$ & 0.001 & 0.980 \\
\hline & Rural & 45 & 80.4 & 11 & 19.6 & $56(22.6)$ & & \\
\hline \multirow{2}{*}{$\begin{array}{l}\text { Monthly Family } \\
\text { Income }\end{array}$} & $\leq R M 3000$ & 7174 & 72.5 & 28 & 28.3 & $102(41.1)$ & 7.965 & 0.005 \\
\hline & $>R M 3,000$ & 126 & 86.3 & 20 & 13.7 & $146(58.9)$ & & \\
\hline \multirow{2}{*}{$\begin{array}{l}\text { Number of } \\
\text { siblings }\end{array}$} & $1-2$ & 50 & 83.3 & 10 & 16.7 & $\begin{array}{c}60 \\
(24.2)\end{array}$ & 0.477 & 0.490 \\
\hline & $>2$ & 149 & 79.3 & 39 & 20.7 & $188(75.8)$ & & \\
\hline \multirow{2}{*}{ Birth order } & Eldest & 59 & 75.6 & 19 & 24.4 & 78 & 1.519 & 0.218 \\
\hline & Others & 140 & 82.4 & 30 & 17.6 & 170 & & \\
\hline \multirow{2}{*}{$\begin{array}{l}\text { Academic } \\
\text { Performance }\end{array}$} & Good & 197 & 80.4 & 48 & 19.6 & 247 (99.6\%) & $0.57^{\mathrm{a}}$ & 0.450 \\
\hline & Poor & 0 & 0 & 1 & 100 & $\begin{array}{c}1 \\
(0.4)\end{array}$ & & \\
\hline \multirow{2}{*}{ Birth Weight } & Normal & 185 & 81.1 & $\begin{array}{l}43 \\
49\end{array}$ & 18.9 & $\begin{array}{l}234 \\
(94 \%)\end{array}$ & & $0.733^{b}$ \\
\hline & Low & 11 & 78.6 & 3 & 21.4 & $\begin{array}{c}14 \\
(6 \%)\end{array}$ & & \\
\hline \multirow{2}{*}{ Health Problem } & Yes & 20 & 90.9 & 2 & 9.1 & $22(8.9 \%$ & & $0.264^{b}$ \\
\hline & No & 180 & 79.7 & 46 & 20.3 & $226(91.1 \%)$ & & \\
\hline \multirow{2}{*}{$\begin{array}{l}\text { Parents marital } \\
\text { status }\end{array}$} & Married & 190 & 79.8 & 48 & 20.2 & $238(96 \%)$ & & $0.692^{\mathrm{b}}$ \\
\hline & Divorced/ Others & 9 & 90.0 & 1 & 10.0 & $\begin{array}{c}10 \\
(4 \%)\end{array}$ & & \\
\hline \multirow{2}{*}{$\begin{array}{l}\text { Bedroom } \\
\text { arrangements }\end{array}$} & Own room & 67 & 79.8 & 17 & 20.2 & $84(33.9 \%)$ & 0.018 & 0.892 \\
\hline & Sharing & 132 & 80.5 & 32 & 19.5 & $164(66.1 \%)$ & & \\
\hline
\end{tabular}

${ }^{a} x^{2}$ is computed using Yates Continuity Correction when more than 1 cell have expected count less than 5

${ }^{b} x^{2}$ is computed using Fisher's Exact Test when 1 cell has expected count less than $5(25 \%)$

be due to of the age differences as the NHMS covered a wider age group of 5 to 15 years old and evidence has also shown that higher prevalence is expected in older age group. ${ }^{2}$ In addition, the difference in the prevalence may also be explained by different methodologies used in both studies. The NHMS was a community based study which involved house to house survey while this study was conducted among adolescents in public schools, therefore omitting adolescents who did not attend school, or those who went to private schools. When compared to adolescents from the United Kingdom within similar age group, the prevalence of mental health problems found in this study was much higher than the Indian adolescents residing in the UK (5\%) as well as the white adolescents (13\%). ${ }^{27}$

In terms of the specific types of mental health problems, $25 \%$ of the adolescents had peer problems while $8.9 \%$ of the adolescents had hyperactivity problem. This has been expected, as during this age, adolescents are forming relationships with others as well as beginning to learn continuing life skills. Peers are known to be influential people in adolescent's life and conforming to peer norms and activities are one of their top priorities. Therefore, failing to meet these relationships may cause anxiety and psychological distress. ${ }^{28}$ This is 
Table III: Independent sample t-test of self-esteem and parenting behaviours on mental health problems in adolescents, $\mathrm{N}=248$

\begin{tabular}{ccccccc}
\hline \multirow{2}{*}{ Variables } & \multicolumn{2}{c}{$\begin{array}{c}\text { No Mental Health } \\
\text { Problems }\end{array}$} & \multicolumn{2}{c}{ Having Mental Health } \\
& Mean & SD & Mean & SD & t & $P$ value \\
\cline { 2 - 7 } & 14.51 & 1.96 & 13.76 & 1.94 & 2.429 & 0.016 \\
Self-Esteem & 27.27 & 2.39 & 27.47 & 3.31 & & $0.469^{\mathrm{a}}$ \\
Parental Care & 10.97 & 2.70 & 10.35 & 2.41 & 1.477 & 0.141 \\
$\begin{array}{c}\text { Parental Allowance Of } \\
\text { Autonomy }\end{array}$ & 11.29 & 2.49 & 12.31 & 2.53 & -2.545 & 0.012 \\
$\begin{array}{c}\text { Parental Control } \\
\text { a Mann-Whitney U Test }\end{array}$ & & & & &
\end{tabular}

supported by Su et. al.(2016) ${ }^{29}$ that showed that peer rejection was associated with anxiety.

A study in Germany has shown that there was a strong association between poverty and emotional and behavioural problems in children, although this can be mediated by parenting style. ${ }^{30}$ Likewise, this study had also demonstrated that there was a significant association between monthly family income and adolescent's mental health problems. Socio-economic status was a major contributing factor, where the odds of adolescents from lower socio-economic background who had mental health problems, doubled compared to those from higher income group. Social disparity based on income differences could lead to segregation between different backgrounds of adolescents, which may influence higher prevalence of peer problems.

High level of parental control would increase the odds of having mental health problems by $20 \%$ which is in line with a study by Schiffrin et.al. ${ }^{31}$ The adolescents are in the stage of exploring and challenging new things and developing their own selfidentity. Thus, having over controlling parents especially when adolescents had less opportunity to express their own feelings and emotion, may result in psychological distress in these adolescents.

Finally, we found that there was significant association between low self-esteem and mental health problems. It was found that having high selfesteem act as a protective factor as shown in the result that the higher the self-esteem scores, the lower the odds of having mental health problems. This is consistent with the finding of a systematic review indicating that low esteem was positively associated with mental health illnesses such as anxiety and depression among children and young people. ${ }^{32}$ People with depression, eating disorders, and substance abuse were also found to have lower self-esteem scores compared to those with other psychiatric comorbidities. $^{33}$

With regard to ethnicity, a study conducted in the United Kingdom has shown that there were ethnic differences when measuring mental health problems among adolescents. This study found that white adolescents had higher score for mental health problems compared to Indian decent adolescents. ${ }^{27}$ In contrast, this study found no significant difference in ethnicity with the presence of mental health problems among the adolescents.

There were no significant association found between having mental health problems and age, housing area, number of children in the family, birth order, academic performance and presence of health problems. In addition, parents' marital status also did not show significant association with the presence of mental health problems in these adolescents. This finding is different from study by Pearce (2013) who found that those who live with reconstituted family or a single parent family were at higher risk of mental health problems. ${ }^{34}$

Table IV: Multiple logistic regression model showing factors associated with mental health problems of the adolescents

\begin{tabular}{|c|c|c|c|c|}
\hline Variable & AOR & $95 \% \mathrm{Cl}$ & Wald & $P$ value ${ }^{a}$ \\
\hline $\begin{array}{l}\text { Income } \\
\leq \mathrm{RM} 3000> \\
\mathrm{RM} 3000\end{array}$ & 2.51 & $1.27 ; 4.90$ & 7.28 & $0.007^{*}$ \\
\hline $\begin{array}{l}\text { Self Esteem } \\
\text { High } \\
\text { Low }\end{array}$ & 0.81 & $0.68 ; 0.96$ & 5.63 & $0.018^{*}$ \\
\hline $\begin{array}{l}\text { High } \\
\text { Parental } \\
\text { Control } \\
\text { High } \\
\text { Low }\end{array}$ & 1.21 & $1.05 ; 1.38$ & 7.22 & $0.007^{*}$ \\
\hline
\end{tabular}




\section{CONCLUSIONS}

One in five school-going young adolescents in Selangor, Malaysia had mental health problems that require early referral and intervention. Adolescents from low socioeconomic background and having highly controlling parents were associated with higher likelihood of having mental health problems. High self-esteem was also found to be a protective factor towards the development of mental health problems. The Malaysian government's approach to increase the nation's income may help to address the mental health problems among adolescents in this country. At the same time, it is also very important to encourage parents, especially mothers to allow some level of autonomy and independence among their adolescents and help them to develop a strong identity. In addition, programs to enhance adolescent's self-esteem and parenting courses designed to help parents to improve their parenting skills are also recommended.

There were a few limitations in this study. This study was conducted among students aged 13- and 14-years old, studying in public schools in Hulu Langat district in Selangor state of Malaysia. Therefore, the findings may not be generalised to adolescents of younger or older age, those studying in private schools or other institutions or other adolescents residing in other parts of Malaysia. Furthermore, this study was based solely on adolescents' self-report without opinions from parents and teachers, which may contribute overestimation of mental health symptoms. Future studies may include parental and teacher's perspective on adolescent's mental health problems. It is imperative to consider parental report on their parenting behaviours instead of depending on adolescents' perspective only. Longitudinal study is also recommended to observe the development or long term manifestation of mental health problems over time.

\section{ABBREVIATIONS}

DALY: Disability Adjusted Life Years

MC: Multicollinearity

NHMS: National Health Morbidity Survey

PBI: Parental Bonding Instrument

SDQ: Strengths and Difficulties Questionnaires

TDS: Total Difficulties Scores

UKM: Universiti Kebangsaan Malaysia

\section{COMPLIANCE OF ETHICAL STANDARD}

\section{Funding}

This research is funded by UKM Medical Centre with Grant Number GGPM-2014-063.

\section{Ethical Approval}

All procedures performed in studies involving human participants were in accordance with the ethical standards of Research Ethics Committee Universiti Kebangsaan Malaysia and with the 1964 Helsinki declaration and its later amendments or comparable ethical standards.

\section{Informed Consent}

Informed consent was obtained from all parents whose children were involved in this study.

\section{Acknowledgments}

We are grateful to all the adolescents and students who took part in this study. We would also like to thank their parents and teachers for their kind cooperation as well as Ministry of Education Malaysia and the school councillors that make this study possible.

\section{Conflict of Interest}

No potential conflict of interest was reported by the authors.

\section{REFERENCES}

1. World Health Organisation (W.H.O.). Adolescent Health Epidemiology. In: Maternal, Newborn, Child and Adolescent Health [online]. Available at: http://www.who.int/ maternal_child_adolescent/epidemiology/ adolescence/en/. Accessed April 14, 2016.

2. Institute for Public Health (IPH). National Health and Morbidity Survey 2015 (NHMS 2015). Vol. II: Non-Communicable Diseases, Risk Factors \& Other Health Problems; 2015.

3. Institute for Public Health (IPH). National Health and Morbidity Survey 2011 (NHMS 2011). Vol. II: Non-Communicable Diseases; 2011. 
4. Ahmad N, MuhdYusoff F, Ratnasingam S, et al. Trends and factors associated with mental health problems among children and adolescents in Malaysia. International Journal of Culture and Mental Health. 2015;8(2):12536

5. Hsien-Jin T. A Survey of Urban Child and Adolescent Mental Health Problems in an Urban Malaysian Population. Malaysian Journal of Psychiatry Ejournal. 2010; Vol 19, No 1 (2010).

6. Idris IB, Barlow J, Dolan A. A longitudinal study of emotional and behavioral problems among Malaysian school children. Annals of Global Health. 2019; 85(1):30, 1-10.Lung F-W, Lee $\mathrm{T}-\mathrm{H}$,

7. Parker G, Tupling, H., Brown, L.B. Parental Bonding Instrument. British Journal of Medical Psychology. 1979;52(1):1-10.

8. Parker, G. (1983) Parental Overprotection: A Risk Factor in Psychosocial Development, Grune \& Stratton, New York. [A monograph describing the development, application and validity of the PBI across a range of psychiatric conditions and other disorders]

9. Muhammad NA, Shamsuddin K, Omar K, Shah $\mathrm{SA}$, Amin RM. Validation of the Malay Version of the Parental Bonding Instrument among Malaysian Youths Using Exploratory Factor Analysis. The Malaysian Journal of Medical Sciences. 2014;21(5):51-9

10. Huang M-F. Parental bonding in males with adjustment disorder and hyperventilation syndrome. BMC Psychiatry. 2012;12:56

11. Turner, H. M., Rose, K. S., \& Cooper, M. J. Parental bonding and eating disorder symptoms in adolescents: The mediating role of core beliefs. Eating Behaviors. 2005;6: 113118

12. Perry JA, Silvera DH, Neilands TB, Rosenvinge $\mathrm{JH}$, Hanssen T. A study of the relationship between parental bonding, self-concept and eating disturbances in Norwegian and American college populations. Eating Behaviors. 2008;9(1):13-24

13. Morgan Z, Brugha T, Fryers T, Stewart-Brown $S$. The effects of parent-child relationships on later life mental health status in two national birth cohorts. Social Psychiatry and Psychiatric Epidemiology. 2012;47(11):1707-15

14. Guillon MS, Crocq MA, Bailey PE. The relationship between self-esteem and psychiatric disorders in adolescents. European Psychiatry: the journal of the Association of European Psychiatrists. 2003;18(2):59-62

15. Lin H. C., Tang T. C., Yen J. Y., et al. Depression and its association with selfesteem, family, peer and school factors in a population of 9586 adolescents in southern Taiwan. Psychiatry and Clinical Neurosciences 2008;62: 412-420

16. Ho C. W. L., Siu L. P. C., Oi K. J. C., Miu.L. M. C. Relationships among mental health, selfesteem and physical health in Chinese adolescents: An exploratory study. Journal of Health Psychology 2010;15(1) 96-106

17. Yaacob S.N., Juhari R, Abu Talib M, Uba I. Loneliness, Stress, Self Esteem and Depression Among Malaysian Adolescents. Jurnal Kemanusiaan, Universiti Teknologi Malaysia. 2009;7(2).

18. Information for researchers and professionals about the Strengths and Difficulties questionnaire. Available at : http:// www.sdqinfo.org/

19. Idris IB, Barlow J, Dolan A, Surat, S. The reliability and validity of the Malay parentreport version of the strengths and difficulties questionnaire. Malaysian Journal of Medical Sciences. 2019;26(1)

20. Vostanis P. Strengths and Difficulties Questionnaire: research and clinical applications. Current Opinion in Psychiatry. 2006;19(4):367-72

21. Goodman A., Goodman R. Strengths and difficulties questionnaire as a dimensional measure of child mental health. J. Am. Acad. Child Adolescent Psychiatry. 2009;48, 4

22. Rosenberg, M. Society and the adolescent self -image. Princeton, NJ: Princeton University Press. 1965.

23. Mohd JB. Validity and reliability study of Rosenberg Self-esteem Scale in Seremban school children. Malaysian J Psychiatry. 2006;15:35-8

24. Passmore NL, Fogarty GJ, Bourke CJ, BakerEvans SF. Parental Bonding and Identity Style as Correlates of Self-Esteem Among Adult Adoptees and Nonadoptees. Family Relations. 2005; 54(4):523-34

25. Murphy E, Wickramaratne P, Weissman M. The Stability of Parental Bonding Reports: A 20Year Follow-up. Journal of affective disorders. 2010;125(1-3):307-15 
26. Department of Statistics, Malaysia. Household Income and Basic Amenities Survey Report, 2016.

27. Dogra N, Svirydzenka N, Dugard P, Singh SP, Vostanis $P$. Characteristics and rates of mental health problems among Indian and White adolescents in two English cities. The British Journal of Psychiatry. 2013;203(1):44-50

28. De Vries, A.L., Steesma, T.D., Cohen-Kettenis, P.T., VanderLaan, D.P., Zucker, K.J. Poor peer relations predict parent and selfreported behavioral and emotional problems of adolescents with gender dysphoria: A crossnational, cross-clinic comparative analysis. European Child Adolescent Psychiatry. 2016;25:579-88

29. Su S, Pettit GS, Erath SA. Peer relations, parental social coaching, and young adolescent social anxiety. Journal of Applied Developmental Psychology. 2016;42:89-97

30. Kaiser, T., Li, J., Pollmann-Schult, M., Song, A.Y. Poverty and child behavioral problems: The mediating role of parenting and parental well-being. International Journal of Environmental Research and Public Health. 2017;14(9), 981

31. Schiffrin H.H., Liss M., Miles-McLean H., Geary K.A. Erchull M.J. Helping or hovering? The effects of helicopter parenting on college student well-being. Journal of Child and Family Studies. 2014;23:548-57

32. Keane L., Loades M. Low self-esteem and internalizing disorders in young people - A systematic review. Child and Adolescent Mental Health. 2017;22:4-15

33. Silverstone PHS, Mahnaz. Low self-esteem and psychiatric patients: Part I - The relationship between low self-esteem and psychiatric diagnosis. Annals of General Hospital Psychiatry. 2003;2:2

34. Pearce A, Lewis $\mathrm{H}$, Law C. The role of poverty in explaining health variations in 7-year-old children from different family structures: findings from the UK Millennium Cohort Study. Journal of Epidemiology and Community Health. 2013;67(2):181-9 